\title{
Piano Concerto in $G$ major by Maurice Ravel: Games and Revelations of the Artist of the Twentieth Century
}

\author{
Zharkova Valeriya ${ }^{1, *}$
}

\begin{abstract}
${ }^{1}$ Department of the World Music History, Tchaikovsky National Music Academy of Ukraine, Kyiv, Ukraine *Corresponding author. Email: zharkova_valeriya@ukr.net
\end{abstract}

\begin{abstract}
This article reviews the Piano Concerto in G major by Maurice Ravel, which is a creative testament of the composer. The Concerto unites the ideas of the game and the beauty, the most important ones according to the composer's thinking. In the first movement, Ravel invites us to "a game with genre," in which the canons of the genre are both preserved and violated at the same time. The second movement introduces us to "a game with styles." The third movement is "a game with the self," because Ravel puts together a mosaic of musical themes that are clearly associated with his earlier works. The composer's games open the opportunity for the audience to touch on the ephemeral world of beauty and charm and to see the Magic garden of our true life. The path to these worlds is the revelation and a gift offered by the dandy composer.
\end{abstract}

Keywords: Maurice Ravel, Piano Concerto in G major, the genre of concert, music games, a mystification in music, Dandyism

Jacopo Belbo was not crazy; he had simply, through his game, hit upon the truth Umberto Eco. Foucault's pendulum

\section{INTRODUCTION}

"The talent that is so cleverly disguised, so capable of deceiving, is unique in music. Everything in Ravel convinces the music lovers of the desire to hide and to not let anyone in on his secret," wrote one of the most authoritative French researchers of Maurice Ravel's work, A. Suarès. [1] It is impossible not to agree with this statement, because, oftentimes, Ravel's shocking manner, paradoxical discernment of compositions and the music itself turn out to be a skillful mystification, a game intended for "the initiates," the rules of which are concealed. Therefore, writing about Ravel is a hard task.

The words pronounced by the maitre of French musicology, Jean-Michel Nectoux, are symptomatic. "The first book about music that I bought was "Ravel" written by V. Yankelevich, and I confess that my admiration for Ravel as the person and the artist has remained intact since that time. [...] I couldn't imagine anyone being able to present a different point of view, a different way of studying such a sublime topic." [2] However, the fundamental monographs about Ravel by V. Yankelevich, A. Roland-Manuel, A. Orenstein, H. Stuckenschmidt and M. Marnat [3] did not stop studying the Ravel's music. It is only in recent decades that the monographs by E. Rousseau-Plotto, C. Goubaud, R. Nichols and D. Sanson [4] have been published. Despite all the differences in approaches, the researchers invariably comment on the deep connection between the composer's artistic ideas and the musical culture of the 20th century. The title of the article that opens the series "Notebooks of Maurice Ravel" "Alchemist of the Future" - sounds like a manifestation of the essence of Ravel's creative discoveries. [5]

Today, we already live in "the future" that has left behind the $20^{\text {th }}$ century and we can say that, although the technical innovations radically change the image of our life, the Ravel's alchemy is our thing. It echoes with our desires for finding the philosopher's stone, looking into the most distant corners of the spiritual space and measuring it with our steps. Various forms of the game run by the composer have become indispensable in such spiritual journeys.

In this context, the Piano Concerto in $G$ major by Ravel opens up the special semantic projections into the depths of the European culture's innermost energies. This Concerto (1929-1931) was conceived simultaneously with the Piano Concerto for the Left Hand in D major (1929-1930). But the concerts were so different from each other in their artistic objectives that Ravel's contemporaries felt that there had been 
"antagonism" between them (M. Long). [6] "It is the day and the night, the Classicism and the Romanticism, the relaxation and the compulsion, the carelessness and the despair", J. Brewer wrote. [7] Thus, it is understandable why musicologists rushed into the depths of "the night" with all their passion, using scientific approaches. They focused their attention on the Piano Concerto for the Left Hand while the Concerto in $G$ major stood aside. The researchers notice that there had been "a special lightness of manner," [8] "dynamic modernity" and "Basque color." [9] Indeed, "the simplicity" of musical material and the correctness of chosen genre model (a $18^{\text {th }}$-century concert) turn out to be a mystification. They hide the real depth, which can be found only using the semantic structures of the game. Let us consider the game's manifestations in the work of Ravel.

\section{ON THE RULES OF THE GAME RUN BY A DANDY COMPOSER}

Maurice Ravel was a true dandy in life and his work. Although Dandyism as a phenomenon in the culture of Europe is widely covered by the Western researchers, [10] it does not often fall into the sphere of musicological reflections. Meanwhile, the projection of the fundamental principles of this influential philosophical concept on the musical life of the late 19th century allows us to talk about a special type of a dandy composer. It emerged in France and identified the artistic guidelines inherent in special type of creative personality. One of the most important representatives of such artists was Maurice Ravel. All Ravel's thoughts and actions were subordinated to the idea of serving the Beauty and fulfilling the need to fight vulgarity in any form.

The books of famous dandies (C. Baudelaire, J. Barbey d'Aurevilly and J.-K. Huysmans) were collected in his library. Ravel's friend, Ricardo Vignes, left a symptomatic note in his diary of 1896 about the Against the Grain by J.-K. Huysmans, "I have finished Against the Grain. It is like the essence of everything that came and is still coming to my thinking." [11] Ravel himself could write the same thing, if he had kept a diary. Not surprisingly, multiple parallels can be seen between the dandy composer and Des Esseintes, the dandy protagonist in the Huysmans novel. Like Des Esseintes, Ravel created a beautiful world based on his life, where all the details were included in sophisticated and endless reflections on the genuine and the mystified, the true and the illusory. Like Des Esseintes, the composer perceived his life as the process where the "front" and "seamy" sides were being interchanged. [12] So, the key to understanding Ravel's personality, aesthetics and style can be found behind all "vice versa" (against the grain) that has marked his life. The most important composer's principle is to balance on the verge of the generally accepted and the individual: to demonstrate traditional rules of the system and make it up-to-date. To argue with tradition or to play tradition becomes the main creative rule of Ravel.

The variety of Ravel's games can be represented by the following types mystification, mosaics and competition. They have common special properties. Each time we become not only participants in the gameplay, but also architects of the unique space. It is because the game exists simultaneously as something real and non-real, something serious and "fairly" pleasant. Without our understanding of the ambivalent essence of everything that is involved in the game, the game is impossible. That is why, for the thinkers of the 20-th century, the characteristics of the game open up new ways of understanding the nature of a human being, and the game itself becomes one of the five most important phenomena of human life (E. Fink). [13]

Ravel's scores reflect his desire to play with various phenomena of the European musical culture (including jazz, music halls and cabaret music). The paradoxical nature of the composer's thinking makes this game with others and with the self either hidden or obvious. Moreover, something that is initially represented as a rule of the game proper often turns out to be a game. This peculiarity of Ravel's thinking is brilliantly characterized by V. Yankelevich: "Ravel falsifies what is really fake." [14] Karol Szymanowski raises the corresponding problem of understanding Ravel's musical works: "But can these games of light, colors and shadows be explained by cold and abstract aestheticism? Of course not! Because, there is depth under this "surface" - transparent, calm and self-focused - and it determines the magical game of colors and light." [15] This artistic principle of the "flickering" and intersecting projections of many semantic layers defines the modernity of Ravel's work and its acute relevance.

As a true dandy who allows the vibrations of the world to pass through him, the composer reacts sensitively to these vibrations, but leaves some of the components "behind the scene." They create the amazing fullness of the musical works of Ravel. His compositions unfold not in a "filtered" ideal dimension, but in a space of flickering opposites (the familiar - the unknown, the expected - the unexpected). This game of the "correspondance" (C. Baudelaire) revealed by the composer activates multiple meanings generated by various contextual fields. Thus, the composer always addresses his game to the listener who has a "culture of distance" and is ready to hear what is beyond the sound in wide semantic areas, arising like a spiritual resonance. The three movements of the Piano Concerto in $G$ major represent different elements of a game that wakes the spiritual echoes. 


\section{THE FIRST MOVEMENT: A GAME WITH GENRE}

In the first movement, Ravel focuses on the concert genre main principles.

The first group of the exposition (Allegramente, rehearsal 1) [16] brings on the function of representation of the soloist (that is traditional for this section of the composition) into the game. The sparkling "Basque theme" is fervently and brilliantly performed by the piccolo flute and then by the trumpet (rehearsals 2-3). It seems that the real soloist does not want to execute his important role. He is "played out" in the arpeggio figurations (the words "Vous m'ennuyez! Vous m'ennuyez!" - "I'm tired of you! I'm tired of you!" are organically tied with the initial phrases of the piano). [17] Then the soloist amuses the audience with quasi-virtuoso glissando over white keys (rehearsals 1-2). However, the "unpretentiousness" of the piano part is deceptive. In fact, the interval of minor second F\#-G fixed in the basic tones of the piano figurations and the "black and white texture" (L. Gakkel), [18] referring to the baroque technique of two keyboards, will organize the subsequent sections of the Concerto and create the unity of its composition.

The importance of F\#-G semitone is emphasized: in the following presentation of the main theme, where the soloist's figures are "folded" into the "slipping" of the triad F\# major and the triad $\mathrm{G}$ major (Cor, Tr-ne, rehearsal 2); in the relation between tonalities of the first and second groups of the exposition (G- F\#); in a tense combination of the note $\mathrm{F} \#$ in bass and the syncopated note $\mathrm{G}$ in the melody of the second group; in the tonal logic of material in the development (rehearsal 15, piano solo) and also in its "breakthrough" in the recapitulation (rehearsal 31, piano solo); in the recapitulation itself and in the tonal logic of the finale of the Concerto. Let us emphasize that it is precisely the conjugation of the tonalities $\mathrm{G}$ major and $\mathrm{F} \#$ major that goes through many of Ravel's other works and is reflected in the key scenes of the opera The Child and the Spells. The black-and-white "slip" technique is further used in all three movements.

In the second group of the exposition, Ravel turns his attention to creation of lyrical images: expressive, filled with "earthly" currents and pure, and perfectly elevated. The first lyrical theme here (rehearsal 4) reveals the expressive world of sharp rhythms and beautiful sounds. This theme is illuminated by the author's subtle irony because everything is presented in an exaggerated manner in the piano part (the intrusive combination of the sounds A-A\#; the illogical syncopations, breaking the naturalness of the figures of a soft nocturnal accompaniment; sudden melodic "bursts" reflected in the orchestral "echoes" (rehearsal 5, rehearsal 6). Obviously, this theme is associated with the Orientalism that has been popular in the nineteenth century and with the jazz that has been fashionable in the beginning of the $20^{\text {th }}$ century.

The second lyrical theme here (rehearsal 7) presents an opposite side of the lyrical sphere - the sublime, far from earthly vanity. We emphasize that this inspiring theme is transmitted from the soloist to low wooden instruments (from rehearsal 9) [19] and its fullsounding texture is colored with the tonality $\mathrm{E}$ major, which is symbolic for the composer. This tonality highlights the most significant lyrical episodes in the opera The Child and the Spells, as well as the famous modulation in the Bolero.

The development (Tempo I, rehearsal 10) intervenes unexpectedly, while bewitching with the magic of rhythm. This is not so much modification of the themes of the exposition but repetition (the lyrical "ideal" theme is absent here). Significant transformations in the themes occur in the recapitulation (rehearsal 18). Thus, Ravel shifts compositional accents that are usual for the classic genre model.

The "Basque theme" is performed here by the soloist for the first time. It has an effective toccata texture. The theme is illuminated with sarcastic grace notes of tall woodwind instruments and semitone "howls" of low wind instruments (Fag, Cor, then Trne). Both themes of the second group also have significant transformations. In the expressive lyrical theme, designated by the composer to be "a Quasicadence," the principle of exaggerated contrast gets the utmost manifestation. This contrast defines long "immersions" in surreal sounds (harp harmonics, foggy chromatic passages in Fag, Fl.picc., $\mathrm{Cl}, \mathrm{Ob}$ ) and sudden expressive breakthroughs of emotion (polytonal "black and white" passages of the soloist). In the pure lyrical theme, Ravel reinforces hidden romantic intentions and turns it into an inspiring Cadenza (from rehearsal 26 before 29).

Thus, both lyrical themes of the exposition attract each other like the opposite charges. They create the image of a concert cadence, represented by reflection (or rather, "folded by mirrors" reflection - "quasicadence"). The soloist takes on the leadership function, as if recalling the main principle of the concert genre. $\mathrm{He}$ is finally exercising his exclusive right to be heard and breaks the repetition chain of musical material. $\mathrm{He}$ takes the listener beyond the bounds of the "fashionable" and "easy" musical environment and stops in front of unknown and mysterious semantic spaces.

So, in the first movement, Ravel retains the fundamental rules of the genre i.e. the role of the leading instrument as a front-runner and the principle of competition between the soloist and the orchestra. However, these principles are interpreted in a new way and activate non-traditional zones of the composition. 
Ravel goes against our expectations, as if wishing to emphasize the fact that the idea of the concert genre proper is that the soloist has a special right to arrange the material.

\section{THE SECOND MOVEMENT: A GAME WITH THE STYLES}

The second movement (Adagio assai) is in sharp contrast to the other movements of the cycle. The restrained "aristocratic" theme of the first section [20], the soft swaying of simple chords in accompaniment, the flickers of major and minor consonances and the variability of the tonal supports remind us of one of Ravel's earliest piano compositions Pavane for a Dead Princess. The associations are amplified by the unexpectedly long sounding of the piano solo (33 measures before rehearsal 1).

At the same time, the characteristic waltz accompaniment creates the effect of combining different meters (3/4 and 3/8) and gives rise to the illusory image of a waltz, repeatedly embodied in the works of Ravel. Noteworthy is also the choice of the main tonality of this movement - E major. This tonality, as mentioned above, is connected with the sublime semantics in the composer's work. Fragile hope and understanding of impossibility of its realization, the joy of expectation and the sadness of knowledge, simultaneously shine through the tender musical texture of the piano part.

The multi-layered musical present containing allusions to the past is also a kind of a self-portrait of the composer. After the kaleidoscope of various phenomena in the music of the first movement, Ravel is looking for his own image, as well as for the image of his "teachers". The enlightened, sad, plastic theme of the soloist, with its pure and strict beauty, reminds us of melodies in the works of Gabriel Fauré, Camille SaintSaens, Jules Massenet, Claude Debussy. Ravel himself pointed out to the themes of V.A. Mozart and, in particular, Mozart's Clarinet Quintet, K. 581 as to the prototype of this theme. However, the original serenity and clarity of the sonority is gradually destroyed by dissonances. They create an intense beating of minor seconds (a characteristic author's trait). This is especially clear in the combination of a quasi-Bach theme with a quasi-classical harmonic sequence in the second sentence of the theme (after $15^{\text {th }}$ measure). It seems that the stylistic metamorphosis that is taking place in music reveals the process of gradual transformation of the alien rule into own, when suddenly the "purely Mozartian" cadence of the theme becomes "the Ravelian one" (rehearsal 1).

The middle section (rehearsal 4 - rehearsal 6) amazes the audience with the sincerity of the sonority after multi-layered allusions of the previous musical content. The unexpectedly pacified string cadence is definitely reminiscent of the Pavane for a Dead Princess (measures 4-1 before rehearsal 5). The differentiation of the musical texture leads to a piercing dramatic culmination (3 measures before rehearsal 6). Powerful tutti shows hidden semantic depths that has only remotely been visible in the surreal sounding of the Quasi cadenza in the first movement. It seems that the game with other styles and with the composer's own style stops for a moment and one can see something immense, inexpressible, incomprehensible in this abyss. Thus, in the context of the easily recognizable stylistic mystifications of this movement, the culmination strikes us with frankness of the author's view exposed as a revelation.

The return of the main theme (rehearsal 6) restores the soft, enchanting beauty of the sound. Thus, the second movement presents Ravel's gaze directed at his favorite composers. At the same time, this gaze reveals such an incomprehensible depth that knows no limits. The game with styles (others' - the composer's) turns out to be the possibility to see something authentic and boundless.

\section{THE THIRD MOVEMENT: A GAME WITH THE SELF}

The third movement makes Ravel's own works a game [21]. Its three main themes are ironically reinterpreted versions of the works created by the composer earlier - the Sonata for violin and piano in $G$ major (1927), the Piano Concerto for the Left Hand (1930) and the Fanfare for the ballet the Fan of Jeanne (1927). This aspect of organization of the finale was hardly noted in Ravel's literature. However, the game with the self can help one understand the concept of the cycle.

The first group of the finale (before rehearsal 3) uses the principles of organizing the introduction and the first group of the Perpetuum mobile of the Sonata for violin and piano. The energetic character, the tonality $\mathrm{G}$ major and the logic of the presentation of the musical elements are also common. In the Concert:

- orchestral introduction (1-4 ${ }^{\text {th }}$ measures);

- toccata texture in the soloist's part (from 5th measure and before rehearsal 1);

- the appearance of the theme (clarinet, rehearsal $1)$;

- re-conducting of the main theme ("the answer") (Fl picc., rehearsal 2).

In the finale of the Sonata:

- introduction (before rehearsal 1); 
- the toccata texture perpetuum mobile (rehearsal $1)$;

- the presentation of the main theme (piano, rehearsal 2);

- re-conducting of the theme ("the answer") (from $8^{\text {th }}$ measure after rehearsal 2).

The parallels can be traced also at the deep level of organization of the material. The main theme in $G$ major breaks down into $G \quad b$ major (the cadence of the clarinet theme) and $\mathrm{G} \#$ minor (the flute's "the answer"). A similar "splitting" of the main tone $G$ is observed in the finale of the Sonata (the oscillation of the tonal supports $A$ b major - $G$ major in its introduction; the polytonal combination $\mathrm{F}$ \# major - $\mathrm{G}$ major in the main section). The harmonic basis of the orchestral refrain and the soloist's part (intervals g- $\#$, d-c \#) in the Concert are also associated with the piano part of the Sonata (rehearsal 1, intervals g-f \#, d-c \#). Thus, this section of the finale appears as the auto-quote.

The theme of the second group is based on the parallel movement of triads along the white keys in the soloist's part (rehearsal 3- rehearsal 7). It clearly reminds us of a sudden beginning of the development in the Concerto for the Left Hand. However, in the Concerto for the Left Hand, the invasion of descending triads has opened the dramatic section, here it opens the cheerful scherzo. The French researcher M. Marnat also catches "a humorous summary of the Concerto for the Left Hand" in this section. [22]

The third theme of the exposition (rehearsal 7) is separated from the previous music by a blow frusta i.e. a striking device used in the beginning of the first movement of the Concerto. Probably Ravel wanted to draw the special attention to this section. He chose as the primary source the Fanfare for the children's ballet the Fan of Jeanne, written in June 1927 by a group of composers who attended the Jeanne Dubost Salon.

The Ravel's Fanfare is a miniature introduction (28 measures) that opened the ballet the Fan of Jeanne that was a parade of parodies staged by young composers. The thunderous rumble of accompanying percussion instruments begins (in the Concert it's the beat of the frusta), anticipates a heroic theme based on the sounds of the triad B major. It is betaken by... the Fl.picc (in the Concert the triad B major is entrusted to Cor). Then, the theme in Fanfare (Ob in $\mathrm{F}$ major) leads to a playful march (the trumpet in $\mathrm{Bb}$ major). In the Concert, the theme (the trumpet in $\mathrm{F}$ major) is directed towards a new contrasting figurative sphere with the unbridled jazz (rehearsal 8, rehearsal 10).

The themes of the exposition flicker in the development (from rehearsal 11), where the soloist's polytonal passages remind us of the "scene of disobedience" from his opera The Child and the Spells. [23] But the author "obediently" returns to order in the recapitulation (from rehearsal 20), while demonstratively observing the simple rules of its construction.

\section{CONCLUSION}

The Piano Concerto in $G$ major is a kind of testament of the dandy composer. No wonder that Ravel has admitted that, of his two concerts, the Concerto in $G$ major is "more Ravel's"! [24] The three movements of this Concerto summarize the composer's creative games.

In the first movement, Ravel invites us to a "game with genre" in which the canons of the genre are preserved and violated at the same time. The composer manifests the conventionality of the game situation: we feel the "on" and "off" of certain genre rules.

The second movement introduces the audience to a "game with styles". The author points out to Mozart's Quintet with Clarinet in G minor as to the main style model, but his recognition is only a mystification. The sublime lyrics of the Adagio incorporates the features of other composers beloved by Ravel: C. Saint-Saens, J. Massenet, G. Fauré and reveals the author's original style. The allusions to the Pavane for a Dead Princess combine the images of the composer's creative youth and his maturity with the whole. The middle section reminds us of the dramatic images of Ravel's work and gives depth to the game. The general culmination (like the "Scene with the Princess" from the opera The Child and the Spells) reveals the most intimate sides of the inner world of its author. For one single moment, Ravel pulls back the curtain covering the bottomless abyss that stretches out "beyond" the game. And this "gesture" defines the uniqueness of his position of the $20^{\text {th }}$-century artist: Ravel masterfully plays with observance of the rules, but these rules do not reveal the true meaning of his works.

The third movement is the master's view on his own works: "a game with the self". Ravel puts together a mosaic of musical themes that are clearly associated with his earlier works.

Hence, the Concerto unites the creative ideas of the composer. What alchemy is behind this music? It is symptomatic that the French researcher Maurice Fleret writes, "Charm: this is the most important Ravelian word, a key word, which, however, does not mean much in today's music. [...] if Ravel pretends to respect all the traditional rules and even invents something in this spirit for the pleasure of demonstrating the obedience, all this is nothing but a game, a mystifying fake, a means of distracting attention and setting up nets: this is to charm you better, child! Even when he plays with the most subtle reminiscences [...], it is 
always in order to open the doors to the known world, where, as the matter stands, everything will soon become unknown, strange and immensely wonderful." [25]

Therefore, the composer's games (mystifications, competitions and unfolding of the mosaic "through taste and style") open the opportunity for the listeners to touch on the ephemeral world of beauty and charm. The path to this world is the revelation and gift offered by Ravel. This opportunity is of particular value today, when information flows and modern communication technologies practically sweep aside such characteristics of our life as charm, fascination and taste, while replacing them with a rigid matrix of fixed rules and restrictions, a predetermined set of available operations. The desire to understand the secret of creative vision of the dandy composer not only reveals the most intimate layer of Ravel's creativity - it becomes the key that opens the treasured door to the Magic garden of our true life, that is always unpredictably new, changeable and unfamiliar.

\section{References}

[1] "Ravel par lui-meme et...Bartok, Jane Bathori, Jean Cocteau", Paris, Ed.de Maule, 1987, p. 210

[2] Jean-Michel Nectoux, "Gabriel Fauré. Lex voix du clairobscur", Paris, Flammarion, 1990, p. 9.

[3] V. Jankelevitch, "Ravel", Paris, Seuil, 1995, 220 p.; M. Marnat, "Maurice Ravel", Paris, Fayard, 1995, 828 p.; A. Orenstein, "Maurice Ravel. Man and musician", New York and London, Columbia University Press, 1975, 291 p.; A. Roland-Manuel, "A la gloire de Ravel", Paris, Ed. de la Nouvelle Revue critique, 1938, 286 p.; H. Stuckenschmidt, "Ravel: variations sur l'homme et l'oeuvre", Paris, J.C. Lattès, 1981, 273p.

[4] F. Porcile, "La belle époque de la musique française (18711940)", Paris, Fayard, 1999, 474 p.; E.Rousseau-Plotto, "Ravel, portraits basques", Paris, Seguier, 2004, 305 p.; C. Goubault, "Maurice Ravel. Le Jardin féerique", Paris, Minerve, 2004, 357p.; D. Sanson, "Maurice Ravel", Paris, Classica répertoire, 2005, 157 p.; Roger Nichols, "Ravel", Yale University Press, New haven and London, 2011, 430 p.

[5] M. Fleuret, "Préface. Un alchimiste du futur" in "Cahiers Maurice Ravel, publiés par la Fondation Maurice Ravel", Paris, Fondation Maurice Ravel, 1985, №1, p.3-6.

[6] M. Long, "At the Piano with Ravel" in "Performing Arts of Foreign Countries", Issue №9, Moscow, Music, 1981, p. 92.

[7] Ibid.

[8] I. Martynov, "Maurice Ravel", Moscow, Music, 1978, p. 242.

[9] V. Smirnov, "Maurice Ravel and his work", Moscow, Music, 1981, p. 322

[10] R.Barthes, "La modes et les sciences humaines" in "Oeuvres completes", Paris, Ed. Du Seuil, 1994, Tome II, P.121-125.; F. Boucher, "Histoire du costume en occident de l'antiquité à nos jours", Paris, Flammarion, 1988, 464 p.; F. Chenoune, "Des modes et des hommes. Deux siècles d'élégance masculine", Paris, Flammarion, 1993, 334 p.; J. Laver, "Histoire de la mode et du costume", Paris, Trames-Hudson, 1990, 287 p.

[11] M. Marnat, "Maurice Ravel", Paris, Fayard, 1995, p.42.

[12] In this regard, Vladimir Yankelevich noted, "Ravel perfectly mastered the art of becoming different and using the real world to hide the inner truth". In: V. Jankelevitch, "Ravel", Paris, Seuil, 1995, p.140

[13] E. Fink, "The main phenomena of human existence", Moscow, Canon, 2017, 432 p.

[14] V. Jankelevitch, "Ravel", Paris, Seuil, 1995, p.49.

[15] "Cahiers Maurice Ravel, publiés par la Fondation Maurice Ravel", Paris, Fondation Maurice Ravel, 1986, №2, p.41.

[16] Sonata form is used in the first movement

[17] This witty remark was made by Gilles Marchais. In: I. Martynov, "Maurice Ravel", Moscow, Music, 1978, p.244.

[18] L. Gakkel also indicates here the continuity with the works of F. Liszt, in particular, "By the brook" and "The fountains of the Villa d'Este". In: L. Gakkel, "Piano music of the twentieth century: Essays", Leningrad, Soviet composer, 1990, p.37.

[19] This timbre is associated with especially personal themes in the composer's work (see, for example, the theme of Mother in the opera The Child and the Spells).

[20] Ternary form is used in the second movement.

[21] The third movement combines the features of the sonata form and the rondo form.

[22] M. Marnat, "Maurice Ravel", Paris, Fayard, 1995, p.659.

[23] This scene is analyzed in detail in the article: V. Zharkova, "The "Author's Word" in the Maurice Ravel's Lyric Fantasy The Child and the Spells" in "Proceedings of the 2nd International Conference on Art Studies: Science, Experience, Education (ICASSEE)", 2018, volume 284. ISSN: 2352-5398

[24] M. Marnat, "Maurice Ravel", Paris, Fayard, 1995, p.658

[25] Cahiers Maurice Ravel, publiés par la Fondation Maurice Ravel", Paris, Fondation Maurice Ravel, 1985, №1, p.5. 